\title{
Uso de textos de la narrativa de autor para desarrollar la lectura en niños con discapacidad intelectual moderada
}

\author{
${ }^{1}$ Claudina Collaguazo Cando, ${ }^{2}$ Elena Díaz Mosquera \\ 1 Universidad Tecnológica Equinoccial, Quito - Ecuador, ccce49531@ute.edu.ec \\ 2 Universidad Tecnológica Equinoccial, Quito - Ecuador, dmen2883@ute.edu.ec
}

Recepción/Received: 29, 09, 2013

Aceptación/Accepted: 26, 11, 2013

Publicado/Published: 20, 12, 2013

\section{Resumen:}

El presente artículo es un aporte didáctico sobre la forma de estimular y desarrollar la lectura en niños con deficiencia intelectual moderada. Se parte de la fundamentación teórica que destaca las habilidades de los estudiantes con deficiencia intelectual, la importancia de la lectura para mejorar las condiciones de aprendizaje, y los cuentos como herramientas que la motivan. Se concluye con la obtención de resultados de habilidades pre lectoras antes y después de llevar a cabo un plan estratégico que permitió establecer avances favorables al proceso de aprendizaje de lectura en niños de Primer Año del Instituto Fiscal de Educación Especial de la ciudad de Quito. Se espera que este artículo sea de utilidad práctica para los docentes de niños con necesidades educativas especiales, que aspiran desarrollar independencia y autonomía en sus estudiantes.

\section{Palabras clave:}

Discapacidad intelectual, habilidades adaptativas, lectura, cuentos, habilidades pre lectoras.

\begin{abstract}
:
The present article is contribution training on how to encourage and develop reading in children with moderate intellectual impairment. It is part of the theoretical basis that highlights the skills of students with intellectual disabilities, the importance of reading to improve learning conditions, and stories as tools to motivate. We conclude with the outcome of pre reading skills before and after carrying out a strategic plan, it is possible to establish favorable developments in the learning process of reading on children of first grade of the Instituto Fiscal de Educación Especial in Quito, Ecuador. It is hoped that this article will be of practical use for teachers of children with special educational needs, who aspire develop independence and autonomy in their students.
\end{abstract}

\section{Keywords:}

Intellectual disability, adaptive skills, reading, stories, pre reading skills. 


\section{INTRODUCCIÓN}

El aprendizaje de la lectura es un proceso integral y complejo que se convierte en una necesidad para recibir y ofrecer información respecto a cualquier hecho o situación del entorno que nos rodea. Este proceso de aprendizaje se fundamenta en investigaciones de la Psicología Evolutiva, la Psicología Cognitiva, entre otras ciencias, que son principios orientadores para la práctica pedagógica en el salón de clases. Ante esta realidad, tanto docentes como padres de familia debemos reflexionar acerca de la lectura y concebirla como una forma de comprender la realidad conforme a las necesidades y expectativas de cada lector.

¿Se puede hablar de aprendizaje lector en niños con deficiencia intelectual moderada? Se considera que los estudiantes con deficiencia intelectual moderada pueden desarrollar habilidades que les permita entender y ajustarse adecuadamente al contexto inmediato. Esta interpretación de la realidad constituye un primer paso para desarrollar el aprendizaje de la lectura y, para ello, se deben considerar recursos valiosos como los cuentos que están al alcance, pero que no siempre son incorporados en el trabajo diario con niños que presentan discapacidad intelectual.

¿Pueden utilizarse los cuentos como un recurso para estimular aprendizajes de lectoescritura en niños con deficiencia intelectual moderada? Los cuentos incluyen en su contenido situaciones reales o fantásticas narradas por los autores, que contienen valores, costumbres, tradiciones o experiencias captadas fácilmente por los niños y que les ayuda a desarrollar su imaginación, creatividad y fantasía, pues aprenden a imitar roles y a relacionar situaciones o hechos del cuento con la vida real. En forma paralela al trabajo con los cuentos, es preciso desarrollar ciertas habilidades que permitan a esta población estudiantil aprovechar de mejor manera estos recursos tan valiosos.

Las interrogantes que se plantean orientaron la investigación realizada, cuyo objetivo consistía en determinar si los niños con deficiencia intelectual moderada pueden desarrollar habilidades pre lectoras a partir de los primeros años de escolarización mediante el empleo de cuentos, habilidades que en los años superiores facilitarían el aprendizaje de la lectura.

\section{MARCO LEGAL}

El Ministerio de Educación y Cultura del Ecuador (2004) plantea como características de un programa de iniciación a la lectura las siguientes:

- Prioriza el desarrollo y enriquecimiento del lenguaje oral como una condición necesaria para llegar con éxito al lenguaje escrito.

- Se apoya en el aprendizaje socializado y la interacción de grupos multiedad.

- Entiende a la inmersión cotidiana y natural en el mundo del lenguaje escrito, como la mejor estrategia para animar a leer. La manera de acercar a niños y niñas al mundo de la lectura es la experiencia directa con las múltiples funciones que cumple el lenguaje.

- Reconoce a la literatura infantil como un recurso imprescindible en el proceso de iniciación a la lectura.

- Adopta el juego y el arte como metodologías principales.

- Promueve el respeto, valoración y enriquecimiento de las culturas locales.

De lo expuesto, se destaca la importancia del lenguaje en las actividades cotidianas que realiza el ser humano; por tanto, los niños con deficiencia intelectual moderada no se excluyen de esta condición para comunicarse e interactuar con su entorno.

\section{MARCO METODOLÓGICO}

La investigación propuesta incluyó una metodología que ayudó a obtener los resultados necesarios para la consecución de los objetivos.

La muestra.- La muestra seleccionada para el efecto estuvo conformada por 8 niños con discapacidad intelectual moderada de uno de los tres paralelos de Primer Año de Educación General Básica del Instituto Fiscal de Educación Especial (IFEE) de la ciudad de Quito. De los 8 niños, 6 son mujeres y 2 son varones; su edad cronológica varía entre 6 y 8 años. Se escogió a los estudiantes de Primer año porque se consideró que es el nivel en el que debe iniciarse el desarrollo de habilidades que, a futuro, beneficiarán el aprendizaje de la lectura.

Para la selección de la muestra se consideraron los siguientes criterios:

- Características de los niños al inicio de la investigación, relacionadas con las áreas de socialización, 
auto cuidado, desempeño académico funcional, autodirección y comunicación.

- Datos referentes al coeficiente intelectual (C. I.) proporcionados por el psicólogo de la institución.

No fue posible considerar al universo completo (todos los niños de los tres paralelos de Primer año), por cuanto el desarrollo de habilidades adaptativas y datos de C.I. no se ajustaban a los requerimientos del proyecto.

El instrumento.- El instrumento utilizado fue una prueba de habilidades pre lectoras elaborada para evaluar experiencias previas al aprendizaje de lectura en niños con deficiencia intelectual moderada. La prueba consta de 8 indicadores claves, cada uno de los cuales incluye de manera específica habilidades que los niños con las características mencionadas, pueden o no desarrollar durante los primeros años de escolarización y que facilitan el aprendizaje de la lectura en los años superiores. Para la puntuación de cada uno de los 8 indicadores se consideraron 5 valores numéricos, cada uno correspondiente a una categoría de frecuencias. La validación de la prueba fue realizada por dos expertos en el tema.

La prueba fue aplicada a los 8 niños de la muestra, antes y después de poner en marcha un plan estratégico, con la finalidad de comparar los resultados. Los 8 indicadores de la prueba son:

\section{Desarrollo de la conciencia fonológica}

Permite a los niños diferenciar los sonidos del lenguaje oral facilitando las posibilidades de comunicación (Centro Andino de Excelencia para la formación de Maestros, 2004). Esta habilidad pre lectora no es aprendida de forma automática; en este proceso se incorpora desde el nacimiento el reconocimiento de los sonidos naturales o artificiales que forman parte del ambiente y que son la antesala para el desarrollo del lenguaje oral. Los aspectos que se evaluaron fueron los siguientes: 1. Emite sonidos producidos por el cuerpo. 2. Produce sonidos onomatopéyicos de animales. 3. Discrimina y señala en gráficos objetos del ambiente que producen sonidos diferentes.

\section{Aproximación y motivación a la lectura}

La aproximación y motivación a la lectura se inicia desde muy tempranas edades, y es para ello determinante la influencia del medio, es decir el ambiente alfabetizador que se muestre al niño poniendo a su alcance y disposición distintas clases de textos (ibid). Cinco aspectos conformaron este bloque: 1. Explora textos y juega a leer marcando con el dedo el recorrido. 2. Demuestra interés, motivación y agrado por la lectura de cuentos. 3. Hace como si leyera manteniendo concordancia con el contenido del cuento, guiándose por las ilustraciones. 4. Mira el cuento de página en página, de principio a fin. 5. Distingue los cuentos de otros textos escritos a partir de su formato y de elementos gráficos.

\section{Interpretación de signos escritos}

En este bloque se incluyeron actividades destinadas a medir la capacidad de los niños para diferenciar las letras de los gráficos. Aquí se evaluaron los siguientes aspectos: 1. Identifica lo leído en el texto escrito y no en las ilustraciones. 2. Asocia palabras con los objetos respectivos, por ejemplo: puerta, mesa, silla y pizarrón.

Reconocimiento del tipo de texto.- Si el niño se encuentra relacionado con diferentes clases de textos, es necesario conocer si es capaz de distinguirlos según su presentación. Aquí se consideró lo siguiente: Reconoce diferentes tipos de textos según su presentación: cuento, revista, libro, prensa escrita.

Extraer información.- Para evaluar la comprensión de un texto se utilizaron indicadores destinados a valorar la capacidad de los niños para reconocer y describir el contenido en base a sus conocimientos previos. Dos aspectos conformaron este indicador: 1. Anticipa de qué se trata un cuento a partir de la portada, título e ilustraciones. 2. Señala algunos elementos del cuento: personajes, lugares, hechos.

Parafraseo.- Para evaluar la reproducción del texto se utilizaron ilustraciones de forma secuenciada, permitiendo la reorganización, aportes y crítica del contenido. Se evaluó lo siguiente: Expresa un relato coherente y organizado observando y ordenando gráficos en forma secuenciada.

Argumentación.- Para la evaluación de este componente se presentaron preguntas clave que los niños debían contestar de forma verbal o corporal, si el caso lo ameritaba; con el fin de conocer sus opiniones o apreciaciones frente a un hecho o acontecimiento. Se evaluaron los siguientes aspectos: 1. Emplea gestos o movimientos corporales para emitir opiniones. 2. Responde a preguntas sencillas. 
Incremento de vocabulario.- En este componente se incluyó el indicador para evidenciar la adquisición de vocabulario nuevo en el niño. La actividad planteada fue: Señala palabras a través de la visualización de imágenes.

Los resultados de la aplicación de la prueba de habilidades pre lectoras al inicio de la investigación, evidenciaron que los niños de la muestra no habían desarrollado habilidades previas al aprendizaje de lectura en sus años iniciales.

La intervención.- Sobre la base de los resultados encontrados, se procedió a poner en práctica la intervención, mediante un plan de cuatro estrategias, cada una con sus correspondientes actividades, recursos e indicadores de evaluación.

El plan estratégico aplicado consta de actividades que estimulan el desarrollo de aprendizajes en los niños con deficiencia intelectual moderada en los años iniciales de su educación, al utilizar recursos educativos y recreativos como los cuentos. Este proceso de estimulación se realizó durante cuatro meses con la mediación intencional y sistemática de la educadora y tuvo como estrategia primordial el acercamiento cotidiano de los niños con el lenguaje y su funcionalidad en la vida personal y social.

Para registrar los avances individuales de los 8 niños de la muestra, se elaboró una ficha de observación semanal estructurada con los indicadores del plan estratégico.

Al finalizar los cuatro meses de intervención, se volvió a utilizar el instrumento elaborado para evaluar a los niños. Los resultados mostraron avances satisfactorios en la mayoría de actividades de estimulación, relacionadas con el desarrollo de habilidades pre lectoras.

Las cuatro estrategias del plan de intervención aplicado fueron las siguientes:

\section{Estrategia 1: El rincón del cuento.-}

La estrategia consistió en crear espacios y oportunidades para que los niños y las niñas tengan contacto diario con la literatura infantil.

Es importante que en la educación de niños con deficiencia intelectual moderada se creen estos espacios, que con la iniciativa y calidez de la maestra pueden de manera práctica y recreativa solventar la participación y agrado de los niños hacia los textos escritos, además de practicar normas de comportamiento y valores como el respeto hacia los libros. Como actividad esencial se pretende simplemente que los niños consideren a los libros y demás textos impresos como parte natural de la vida cotidiana.

\section{Estrategia 2: La audición y el lenguaje oral.-}

La estrategia consistió en organizar un plan para estimular el desarrollo del lenguaje oral de los niños. Este plan incluyó una secuencia de actividades que estimulen las destrezas de hablar y escuchar y que, de alguna manera, también enriquezcan su vocabulario.

Un complemento importante es crear espacios e incrementar oportunidades para que los niños puedan escuchar canciones, cuentos, poesías y cualquier otra forma de literatura infantil, que se puede encontrar en cedés, radio, video.

En este contexto, la escuela y el aula tienen el compromiso fundamental de crear espacios, dentro de un clima afectivo y de respeto, que inviten y promuevan la interacción verbal entre los niños, las niñas y los docentes. Estos espacios permiten que los niños perciban a la maestra como alguien con quien pueden interactuar y no únicamente como la autoridad en el salón de clase.

\section{Estrategia 3: El juego dramático.-}

Esta estrategia consistió en crear oportunidades para que a través del juego los niños representen o simulen actividades de la vida diaria. Por ejemplo: cocinar, ir de compras a la tienda, lavar ropa, etc.

Para lograr este propósito se requiere disponer de juguetes y materiales que les permitan representar o personificar diversas actividades y situaciones reales.

Es indispensable contar con muestras o materiales impresos propios de cada actividad que quieran imitar los niños. Así por ejemplo: Si juega a cocinar, los juguetes deben ser rotulados: cocina, ollas, cucharas, tazas, platos, etc. Si juega a ir de compras, se debe disponer de dinero didáctico, cajas o envolturas de productos comestibles.

Estrategia 4: La hora del cuento.- 
La hora del cuento es una estrategia programada que debe ser divertida para los niños. Así se logrará despertar el interés por los libros y las imágenes que forman parte de estos textos literarios como herramientas necesarias para iniciar con éxito el aprendizaje de lectura.

Es preciso considerar una hora semanal para contar cuentos a los niños, que despierten su interés por la literatura infantil y por la lectura. En el proyecto realizado, esta estrategia consistió en leer o narrar en voz alta cuentos infantiles que aportaron con valores, estimularon la imaginación, la creatividad y, sobretodo, la autoestima en los niños con deficiencia intelectual moderada, puesto que se sienten muy felices y capaces cuando toman un texto, lo manipulan y juegan a leer.

\section{RESULTADOS Y DISCUSIÓN}

La hora del cuento permite que el niño comparta y socialice con el narrador y los compañeros. Estas fueron las situaciones que se pretendieron reforzar en el trabajo de investigación, con la finalidad de que los estudiantes entablen de manera divertida y lúdica relaciones sociales, aprendan a compartir momentos interesantes, a manipular textos que llamen su atención y curiosidad, a descubrir que, a más de los interesantes gráficos, existen también palabras que forman parte del cuento y que nos enseñan cosas nuevas y agradables.

¿Cómo contar un cuento? Debido a que el cuento es una de las primeras experiencias de los niños con el lenguaje oral y escrito, leer cuentos es una clave para motivar a la lectura y escritura. Si la persona que lee un cuento es capaz de lograr que los pequeños se sientan atraídos o identificados con los personajes, los paisajes, las ideas principales o las reflexiones, logrará que a futuro quieran leerlos o reproducirlos por sí mismos (Centro Andino de Excelencia para la formación de Maestros, 2004).

Considerando lo expuesto, se requiere prever el tipo de cuento que se presenta al niño, de acuerdo a su edad; para los de menos edad se deben escoger cuentos más breves y simples desde el punto de vista estructural (poca cantidad de episodios). Por otra parte, es importante acompañar el cuento con ilustraciones más grandes que apoyen la comprensión y ayuden a mantener la atención y el interés en el relato. De la experiencia obtenida a través de la investigación realizada, se desprende que las imágenes grandes de un cuento, elaboradas por la maestra o por los padres de familia, captan la atención de un niño con deficiencia intelectual moderada y la narración permite establecer reflexiones que, aunque cortas y limitadas, desencadenan emociones placenteras en los pequeños.

Los cuentos son textos cuyo contenido aborda de manera significativa la cultura, tradiciones, valores y características de los seres humanos, transmitidos de generación en generación. Puede afirmarse que los cuentos tienen un gran valor educativo y que pueden emplearse para generar nuevos aprendizajes e introducir nuevos conceptos (Centro Andino de Excelencia para la formación de Maestros, 2004).

\section{CONCLUSIONES Y RECOMENDACIONES}

Con esta investigación se demostró que los niños con deficiencia intelectual moderada de Primer Año de Educación General Básica del Instituto Fiscal de Educación Especial pueden mejorar su atención, memoria y concentración con la lectura de cuentos. Al respecto, se evidenció que:

Siempre y casi siempre, dentro de la categoría de frecuencias establecida, los niños identificaron personajes y lugares importantes de un cuento.

Explorar textos y jugar a leer, mostrar agrado por la lectura de cuentos, diferenciar los tipos de texto, identificar qué se debe leer en el texto y no en las ilustraciones, son habilidades que pueden desarrollarse con la lectura de cuentos, y permitir que los niños con deficiencia intelectual moderada interactúen con la literatura.

Los resultados mostraron que los niños de Primer Año desarrollaron habilidades pre lectoras, las cuales facilitarían el aprendizaje de lectura en años superiores.

Los pequeños incrementaron su vocabulario, pues fueron capaces de señalar en los cuentos leídos, imágenes de personajes, lugares o hechos importantes.

La lectura de cuentos en ambientes adecuados y agradables permite desarrollar en los niños con deficiencia intelectual moderada, atención a normas de comportamiento, actitudes de respeto a sus compañeros, cuidado y orden del texto de lectura, y 
gusto porque le relaten un cuento.

\section{REFERENCIAS BIBLIOGRÁFICAS}

Centro Andino de Excelencia para la formación de Maestros. (2004). Niñas y niños aprenden a leer y escribir. Perú: Oficina Regional de Desarrollo Sostenible.

Ministerio de Educación y Cultura, Ecuador. (2004). Iniciación a la lectura, p. 15. Quito: Mariscal.

\section{BIBLIOGRAFÍA CONSULTADA}

Colomer, T. y Durán, T. (2001). Didáctica de la lengua en la educación infantil. Madrid: Síntesis.

González, J. (2003). Discapacidad Intelectual: Concepto, evolución e intervención psicopedagógica. Madrid: Ed. CCS.

Junta de Andalucía. (n.d.). Manual de atención al alumnado con necesidades específicas de apoyo educativo derivadas de discapacidad intelectual. Andalucía: Consejería de Educación.

Ministerio de Educación, Ecuador. (2013). Currículo de Educación Inicial. Quito: www.educacion.gob.ec

Ministerio de Educación y Cultura, Ecuador. (2004). Iniciación a la lectura, p. 15. Quito: Mariscal.

Suárez, B. (2010). Estrategias Psicomotoras. México: Limusa.

Troncoso, María V., del Cerro, M.M. (1999). Síndrome de Down: lectura y escritura. Barcelona: Masson. S.A. 